\title{
|MÉTODO PARA ELABORAÇÃO DE PROJETOS PARA PRODUÇÃO DE VEDAÇÕES VERTICAIS EM ALVENARIA
}

\author{
Monserrat DUEÑAS PEÑA \\ Arquiteta e Urbanista, Mestre em Engenharia Civil, \\ Diretora da Petra Arquitetura e Racionalização Ltda \\ monserrat@petra-arquitetura.com
}

\section{Luiz Sérgio FRANCO}

Engenheiro Civil, Doutor em Engenharia Civil, Professor Associado da Escola Politécnica da Universidade de São Paulo

luiz.franco@poli.usp.br

\section{RESUMO}

Este artigo resume os resultados de uma pesquisa de mestrado cujo objetivo principal foi o desenvolvimento de um método para a elaboração de projetos para produção de vedações verticais (PPVV).

Para o desenvolvimento deste trabalho de pesquisa foram realizados estudos de caso que apresentaram um panorama das interfaces entre as empresas construtoras, empresas projetistas e equipes de produção mediante a introdução do PPVV.

Este trabalho tem um caráter prático e esclarecedor em relação ao desenvolvimento do PPVV e sua inserção no processo de projeto, objetivando estabelecer diretrizes para seu desenvolvimento e contratação.

Palavras-chave: construção de edifícios, projeto para produção, vedações verticais

\section{ABSTRACT}

This paper summarises the results of a Master's research that aimed mainly to develop a method of masonry walls designing for production (MWDP).

In order to perform this research some case studies were carried out, which show a panorama of the interrelations among contractors, design firms and production teams when a MWDP is implemented.

The work has a practical and clarifying character concerning the MWDP process and its insertion into the building design process as a whole, aiming to establish guidelines on how to contract and develop the MWDP.

Keywords: building construction, design for production, partitions and facades 


\section{INTRODUÇÃO}

A introdução de sistemas de gestão da qualidade nas empresas construtoras tem se intensificado nos últimos anos. Esta preocupação das empresas está fortemente vinculada às mudanças tecnológicas, de mercado e do perfil do consumidor, que está mais exigente. Esta situação criou a necessidade de as empresas buscarem uma maior eficiência nos seus processos de produção, os quais acabaram sofrendo alterações em todas as suas áreas de atividade (planejamento, projeto, execução, controle, suprimentos, serviços, recursos humanos e assistência técnica).

Muitas empresas construtoras já perceberam a importância da fase de projeto, uma vez que esta interage diretamente com todas as demais atividades, bem como sua potencialidade para reduzir custos e racionalizar a produção, tornando a empresa mais competitiva no mercado. O projeto deve conter as especificações do produto a ser construído, os meios estratégicos, físicos e tecnológicos necessários para executar a obra de forma racionalizada.

Segundo o Construction Industry Institute (CII, 1987), as decisões tomadas nas fases iniciais do empreendimento, principalmente na fase de concepção e projeto, são as que têm maior capacidade de influenciar o custo final.

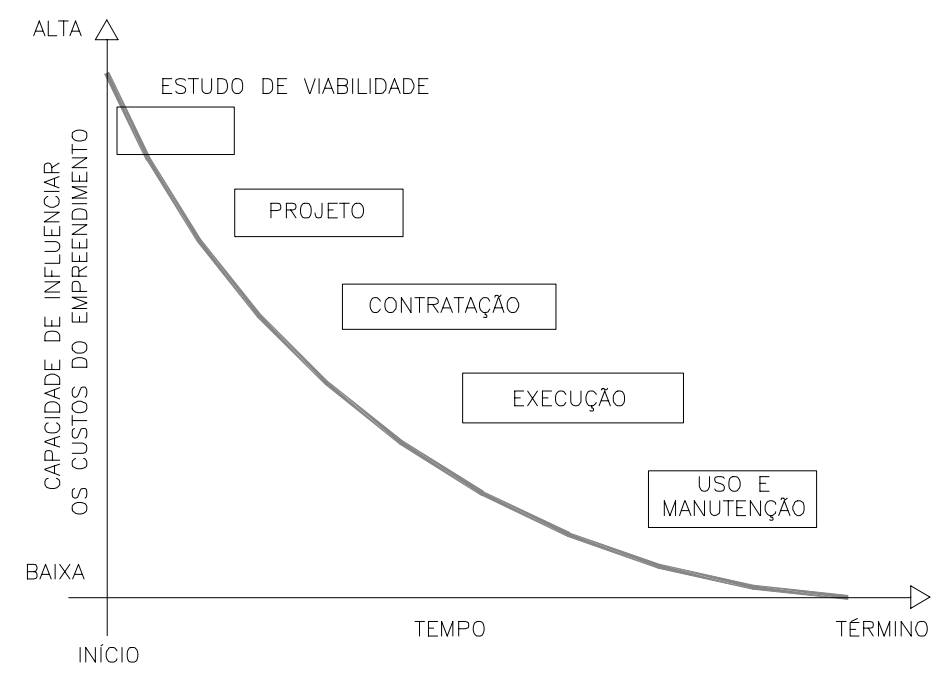

Figura 1. Capacidade de influenciar o custo final de um empreendimento de edifício ao longo de suas fases (CII,1987)

Melhado; Violani (1992) apontam que "para se obter sucesso em um empreendimento, o projeto não pode ser resumido à caracterização geométrica no papel da obra a ser construída. O projeto deve conceber, além do produto, o seu processo de produção; (...) deve assumir o encargo fundamental de agregar eficiência e qualidade ao produto".

Sabbatini (1989) ressalta a importância da elaboração do projeto para produção do edifício (ou de suas partes), no qual “(...) são definidas as técnicas construtivas (e também os métodos, no caso do objeto do desenvolvimento ser um processo ou um 
sistema construtivo) e projetados os detalhes de execução (...) que irão permitir a construção do edifício ou de suas partes em acordo com o prescrito na concepção geral". Segundo esse mesmo autor "o projeto de produção do edifício evolui em ciclos iterativos, iniciando-se por um projeto preliminar e avançando progressivamente até a solução consolidada".

O projeto para produção das vedações verticais, especificamente, interfere na racionalização do edifício como um todo. Segundo Barros (1998), o subsistema de vedação vertical corresponde a, em custo, $3 \%$ a $6 \%$ de todo o edifício. Considerando a sua interface com os demais subsistemas (estrutura, instalações, revestimentos, entre outros) este custo passa para mais de $20 \%$ do custo total do edifício. No subsistema de vedação vertical se observam ainda os maiores índices de desperdício de materiais e mão-de-obra, e também, os maiores índices de patologias.

Em função de suas interfaces com os demais subsistemas do edifício, a vedação vertical é de grande importância na racionalização da obra como um todo. $\mathrm{O}$ projeto de vedação deve ser elaborado de forma sistêmica, simultaneamente aos demais projetos (arquitetura, estrutura, instalações, etc), permitindo assim uma coordenação das informações e das soluções técnicas a serem adotadas.

A racionalização da vedação vertical, através dos projetos para produção, é necessária para se obterem o planejamento e a organização da produção da obra, aumentando a produtividade, diminuindo os custos, evitando problemas decorrentes da interferência de serviços entre os subsistemas, o retrabalho, desperdícios e futuros problemas patológicos.

Nos últimos anos um número significativo de empresas tem elaborado e utilizado o projeto para produção das vedações verticais. Apesar da sua importância, não existem métodos consolidados para o desenvolvimento do projeto de vedações verticais, tendo cada escritório desenvolvido um método próprio, a partir de sua experiência em particular. Este projeto, por possuir um papel integrador das informações dos demais projetistas, deve ser elaborado com base em um método de desenvolvimento, para o qual pretendeu-se contribuir com o desenvolvimento deste trabalho.

\section{METODOLOGIA}

Para estruturar a elaboração do método a ser proposto foram realizadas revisões bibliográficas e estudos de caso envolvendo entrevistas com empresas construtoras, equipes de produção e empresas projetistas.

A partir dos dados obtidos e da experiência profissional da autora ${ }^{1}$ foi definido e adotado um padrão do processo de desenvolvimento de projetos e do escopo do PPVV, que serviram de base para a elaboração do método desenvolvido.

Este método terá um papel estratégico para o desenvolvimento dos projetos, servindo como base referencial para projetistas e como ferramenta de controle para as empresas contratantes.

\footnotetext{
${ }^{1}$ A autora atua há 10 anos como coordenadora de projetos, na elaboração de projetos para produção de vedações verticais e projetos de arquitetura, e é sócia-diretora da empresa Petraa Arquitetura e Racionalização Ltda, especializada em projetos para produção de vedações verticais e arquitetura racionalizada.
} 


\section{PROJETO PARA PRODUÇÃO DE VEDAÇÕES VERTICAIS (PPVV)}

Dentre os projetos desenvolvidos de um empreendimento, o PPVV ganhou um papel de destaque no que diz respeito à gestão da produção. Este projeto traz incorporada uma síntese dos demais projetos do empreendimento, já compatibilizados, numa linguagem técnica voltada para a gestão racionalizada da produção, estabelecendo uma interface única entre todos os agentes envolvidos.

Para Franco (1998) o projeto de vedação vertical é uma peça de extrema importância para a implantação de tecnologias construtivas racionalizadas e este projeto deve ser concebido dentro uma visão sistêmica, "não se restringindo unicamente à melhoria do comportamento dos componentes da vedação vertical, mas inserindo o funcionamento da vedação vertical no edifício e a sua produção na organização e racionalização dos demais subsistemas que compõe a edificação".

Além de apresentar uma integração significativa entre projeto e produção, o PPVV apresenta um papel estratégico decorrente das várias interfaces estabelecidas do subsistema de vedações verticais com os demais subsistemas. Através da compatibilização e análise crítica das interfaces envolvidas é possível racionalizar a produção e melhorar o desempenho do edifício como um todo.

Franco (2002) acredita que projeto de vedações deve estar baseado na análise conceitual caracterizada a seguir.

\section{CONCEITUAÇÃO DO RELACIONAMENTO COM A ESTRUTURA}

A interface entre a estrutura e as vedações verticais, particularmente, tem sido muito discutida nos últimos anos. Este fato se deve à evolução dos sistemas estruturais que contam com novos materiais e novas situações de desempenho, repercutindo diretamente sobre as vedações verticais.

Para Franco (1998) "as mudanças ocorridas na forma de conceber as estruturas e a aplicação dos novos materiais têm aumentado a importância da deformabilidade, elasticidade ou capacidade de acomodar deformações, por um lado e da resistência mecânica por outro, mesmo para os elementos construtivos empregados apenas como de vedação, para fazer frente às novas condições de deformação impostas pelas estruturas de concreto armado".

Ainda segundo o mesmo autor, a análise do projeto estrutural no qual irá se inserir a vedação vertical é de fundamental importância para determinar tanto as características inerentes ao vedo que ela compõe, como dos detalhes construtivos necessários ao bom desempenho deste, frente ao nível de solicitações esperadas.

O relacionamento da estrutura com as vedações verticais tem uma repercussão significativa na obra como um todo. Devido a este fato, no PPVV este relacionamento deve ser analisado minuciosamente e, a partir da análise desta interface, serão estudados e detalhados os pontos críticos entre os subsistemas, tais como: tipos de ligação com a estrutura, necessidade de absorver deformações, situações de paredes com solicitações específicas como: paredes sobre lajes, paredes sobre balanços; juntas de trabalho e separação e reforços de revestimentos.

Além dos pontos levantados, a análise do relacionamento da estrutura com as vedações verticais têm um papel decisivo no planejamento da seqüência de atividades da obra, o qual deverá atender às necessidades de desempenho das 
vedações que impõe um tempo mínimo para o início de sua execução e conseqüente execução dos demais subsistemas a ela relacionados, minimizando a transmissão de esforços para as vedações durante a execução da obra.

A análise dos conceitos relacionados à estrutura apresentados é essencial para a elaboração do PPVV e deve ser relacionada à conceituação dimensional e de produção apresentados a seguir.

\section{CONCEITUAÇÃO DIMENSIONAL}

Estes conceitos são decorrentes da análise da coordenação dimensional entre os vários elementos que compõe a vedação vertical e entre estes e os elementos dos outros subsistemas do edifício.

Para Franco (1998) a coordenação dimensional e modular "levaria a padronização dos detalhes construtivos, que além de facilitar a execução e controle dos mesmos, permitiria a padronização das soluções e o desenvolvimento de alternativas cada vez melhores para as diversas situações padrão".

Durante a elaboração do PPVV são analisadas e compatibilizadas as medidas de blocos, juntas de argamassa, vãos de esquadrias, revestimentos, impermeabilizações, vergas e contra-vergas, etc. A adoção da coordenação dimensional na etapa de projeto permite ajustar as medidas de todos os componentes da alvenaria e dos subsistemas a ela relacionados intensificando a racionalização da produção e diminuindo as incompatibilidades e improvisações na fase de execução.

Poucos sistemas e projetos encontram-se desenvolvidos dentro do conceito de coordenação modular, que tornaria a coordenação dimensional mais simples e fácil de ser obtida efetivamente nas obras.

\section{CONCEITUAÇÃO DA PRODUÇÃO}

Um dos principais objetivos da elaboração de um projeto de vedações verticais é estudar e definir as tecnologias de produção. (FRANCO, 1998)

Os conceitos de produção analisados no PPVV devem prever o desempenho da vedação vertical e dos subsistemas a ela relacionados, dentro de uma visão técnica.

Para tanto, no PPVV, devem ser definidas e detalhadas, após uma análise técnica e sistêmica, todas as tecnologias a serem utilizadas.

Sabbatini (1998), afirma que "para fazer uma escolha técnica é necessário dominar o conhecimento relacionado com a tecnologia de produção daquelas alternativas que estão sendo objeto de análise". Deve-se, portanto, de acordo com esse autor, compreender as características principais, as exigências de cada tecnologia inovadora, as suas deficiências e limitações, as soluções alternativas para evitar problemas.

Para a elaboração do PPVV devem ser definidas as soluções técnicas, os materiais a serem empregados, sua sequiência de elaboração e procedimentos executivos. Estas definições partem da análise estrutural e dimensional, da análise crítica dos projetos e da análise das interfaces dos demais subsistemas com a alvenaria. 
A partir destas análises são definidos e detalhados conceitos de produção tais como: família de blocos a ser utilizada, tipo de argamassa, tipos de amarração entre alvenarias, fixação da alvenaria a estrutura, juntas de trabalho, instalação das esquadrias, relação da alvenaria com instalações(embutimento ou criação de shafts), vergas e contra-vergas, utilização de componentes pré-moldados, etc.

Estas definições são essenciais para o início do desenvolvimento do PPVV e para a elaboração dos procedimentos técnicos e definição da seqüência executiva. Isto é essencial para que o PPVV tenha coerência com a forma de executar. Complementando o projeto para produção é necessário que sejam definidos conceitos ligados ao planejamento e controle da obra, tais como: técnicas de execução, seqüências de execução, arranjo de canteiro, sistemática de transporte, entre outros. Alguns destes itens são desenvolvidos geralmente pela equipe de produção da obra, às vezes de forma não muito metódica, ou supridos parcialmente pelos procedimentos da empresa. Estes, porém, não costumam ser escopo do serviço dos escritórios que se dedicam a desenvolver o PPVV.

O conteúdo específico do PPVV e sua forma de elaboração foram pouco discutidos dentro do meio acadêmico. Dentro deste enfoque, destacam-se os trabalhos desenvolvidos através dos convênios EPUSP/SCHAIN CURY (1995) e EPUSP/ENCOL (1991). No âmbito dos convênios com estas empresas foram desenvolvidas pesquisas que resultaram em diretrizes e recomendações para a elaboração do PPVV. Estes documentos apresentam um excelente conteúdo técnico e auxiliaram no desenvolvimento do método proposto no item 4 . No entanto, estes documentos não apresentam uma sistemática de desenvolvimento de projeto detalhada. Pela sua importância, a relação destes documentos se encontra na bibliografia.

No estado de São Paulo, o PPVV vem sendo elaborado por um número reduzido de empresas de projetos dentro, que possuem padrões de desenvolvimento e de conteúdo variados, baseados na experiência profissional particular de cada escritório. Desta forma, encontram-se no mercado projetos para produção de vedações verticais com enfoques distintos, que nem sempre atendem às necessidades técnicas e organizacionais do empreendimento.

Para caracterizar o conteúdo do PPVV e seu processo de elaboração foram realizados os estudos de caso caracterizados a seguir.

\section{ESTUDOS DE CASO}

Com o intuito caracterizar o conteúdo e o processo de desenvolvimento dos projetos de vedações verticais, foram realizados estudos de caso.

Estes estudos envolveram visitas às empresas que desenvolvem projetos para produção e às construtoras que os empregam. Além disso, foram realizadas também visitas às obras das construtoras envolvidas, para analisar a postura de cada um dos integrantes do processo de produção de edifícios.

Para cada um dos principais agentes, procurou-se conhecer diferentes aspectos:

EMPRESA DE PROJETO: seu ponto de vista no que se refere à importância do projeto para produção, grau de detalhamento do projeto desenvolvido pela empresa, relação cliente-projetista e forma como o projetista visualiza o cliente. 
EMPRESA CONSTRUTORA: ponto de vista no que se refere à importância estratégica e ao papel do projeto para a empresa, qual o agente motivador da procura de projetos para a produção, qual o impacto deste tipo de projeto na gestão de produção da empresa e no seu desempenho e qual a relação estabelecida com o projetista.

EQUIPE DE PRODUÇÃO: ponto de vista no que se refere ao impacto e dificuldades encontradas na implantação do projeto para produção, qual a relação estabelecida com o projetista e como é feita a retroalimentação do projeto.

Ressalta-se que, para as visitas realizadas, foram elaborados e aplicados questionários específicos.

A relação completa dos dados obtidos pode ser encontrada em Dueñas Peña (2003). A seguir serão apresentadas as considerações gerais dos estudos de caso.

\section{CONSIDERAÇÕES GERAIS DOS ESTUDOS DE CASO}

Os estudos de casos apresentados, apesar de constituírem uma amostragem reduzida quanto ao número de empresas construtoras entrevistadas, caracterizaram, de acordo com a experiência profissional da autora, uma visão representativa da repercussão do PPVV no mercado.

Alguns dados citados nos estudos de caso, pela sua importância para o desenvolvimento deste trabalho, serão discutidos a seguir.

Nos estudos de caso, foi possível constatar que o PPVV se encontra padronizado e consolidado no mercado. Há vários anos, quando se deu início ao desenvolvimento do método a ser apresentado, o PPVV ainda não era conhecido pela grande maioria das empresas construtoras, porém o seu conteúdo era muito próximo ao dos projetos que vêm sendo elaborados atualmente.

As diferenças encontradas entre os PPVV produzidos pelos escritórios especializados no mercado concentram-se basicamente nos seguintes itens: representação gráfica; análise técnica e conceitual; detalhamento; procedimentos; especificações técnicas e reatroalimentação do projeto.

Um dos itens mais significativos e representativos do PPVV é a análise técnica e conceitual. Infelizmente, nem todos os PPVV encontrados no mercado levam em consideração este item. Tal fato se deve, basicamente, à formação técnica dos representantes das empresas; desta forma, o PPVV elaborado por estas empresas se apresenta basicamente como um projeto de produto. Indiscutivelmente, apesar desta deficiência técnica, os PPVV elaborados apresentam um impacto positivo no processo de projeto e de produção através de seu caráter compatibilizador uma vez que, para a elaboração do PPVV, é necessária a compatibilização de todos os projetos envolvidos no empreendimento.

Pelo mesmo motivo, o detalhamento e elaboração dos procedimentos e especificações técnicas ficam comprometidos e variam muito de acordo com cada projetista.

A eventual deficiência técnica destes projetos, na prática, prejudica diretamente e de forma mais significativa as empresas construtoras de pequeno e médio porte que contam com o suporte técnico do projeto para produção. As empresas de 
grande porte são menos prejudicadas porque normalmente já têm padrões próprios de execução e detalhamento. A falta de procedimentos e detalhamento técnico do PPVV contradiz os conceitos de projeto para produção, transformando uma parte dos PPVV elaborados atualmente em projetos de modulação racionalizada e compatibilizada.

A grande maioria das empresas construtoras ainda não tem consciência das potencialidades de racionalização do PPVV, sendo em grande parte, responsáveis pela deficiência técnica dos projetos contratados. Cabe às empresas contratantes ter uma postura mais consciente e crítica ao contratar os PPVV, forçando os projetistas a oferecer um produto mais detalhado e abrangente tecnicamente.

Um dos pontos críticos e representativos identificado nos estudos de caso se refere à coordenação de projetos. A coordenação dos projetos não faz parte do escopo do PPVV, mas esta função eventualmente pode ser atribuída ao projetista de produção mediante contratação específica. O PPVV tem por essência um caráter compatibilizador e, dentro do processo de projeto, o projetista para produção acaba assumindo algumas funções atribuídas ao coordenador de projetos, seja pela ausência de um coordenador ou pela ineficiência do responsável pela coordenação. O projetista para produção, devido ao seu papel compatibilizador e formação técnica, tem um perfil adequado para exercer a coordenação, embora tal potencialidade ainda seja pouco explorada no mercado.

Outro ponto crítico identificado está relacionado a entrega do PPVV para a equipe de produção. Mesmo quando a equipe de produção está familiarizada com o PPVV, a entrega e apresentação do projeto para a equipe de produção, por parte do projetista, é de extrema importância para eventuais esclarecimentos técnicos pertinentes ao projeto específico e para garantir o retorno do impacto do PPVV para futuras melhorias.

De modo geral, a entrega do PPVV para a equipe de produção é feita para o departamento de projeto ou responsável da construtora em função de procedimentos da empresa, inviabilizando o contato direto do projetista de alvenaria com a equipe de produção. Da mesma forma, qualquer solicitação da equipe de produção é feita por intermédio do mesmo departamento.

Nas empresas pequenas ou de médio porte o contato com a equipe de produção é feito diretamente com mais freqüência, facilitando a retroalimentação do PPVV e agilizando a resolução de eventuais solicitações.

A entrega do projeto e acompanhamento da sua utilização está diretamente ligada à retroalimentação do projeto mencionada anteriormente como um dos itens diferenciais entre os PPVV encontrados no mercado.

Nem todos os escritórios de projeto têm a preocupação de acompanhar o impacto do PPVV na equipe de produção e obter informações para melhorias do projeto. $\mathrm{E}$ os escritórios que oferecem e até mesmo insistem neste serviço nem sempre conseguem exercê-lo, devido a burocracias relacionadas a procedimentos de entrega de projetos e até mesmo pela falta de interesse da construtora ou da própria equipe de produção. 
Desta forma a retroalimentação fica vinculada ao surgimento de problemas, para os quais o projetista é solicitado, ou através de relatórios de avaliação de projetos elaborados pelas empresas construtoras, quando encaminhados aos projetistas.

Por fim, cabe ressaltar o impacto do PPVV no processo de projeto. A introdução do PPVV no processo de projeto, no início, ocorria na grande maioria das vezes na etapa de projeto executivo; raramente o PPVV era solicitado na fase de anteprojeto. Atualmente, as empresas têm solicitado o PPVV no início do desenvolvimento do anteprojeto. Esta mudança contratual se deve à constatação, por parte das construtoras, do aumento significativo do potencial de racionalização do PPVV quando introduzido nas fases iniciais do desenvolvimento dos projetos.

Tal postura implica, eventualmente, em um processo de projeto um pouco mais demorado e participativo; no entanto, os resultados são indiscutivelmente satisfatórios mediante a elaboração de projetos já compatibilizados e detalhados de acordo com a tecnologia a ser utilizada.

Alguns projetistas ainda apresentam dificuldades e até mesmo resistência ao desenvolvimento participativo e simultâneo dos projetos, mas esta postura vem mudando gradativamente, em função do estabelecimento de parcerias e, principalmente, pelas novas exigências de mercado relacionadas à qualidade e a novos conceitos de desenvolvimento de projetos racionalizados.

\section{MÉTODO PARA ELABORAÇÃO DO PPVV}

\section{DEFINIÇÃO DO PRODUTO}

De acordo com os dados levantados para a elaboração do método, o escopo do PPVV pode ser variável. A variação do escopo se deve basicamente:

- ao perfil do cliente: estruturas organizacionais e patamares tecnológicos diferenciados;

- à tipologia do empreendimento: residencial, comercial, serviços e institucionais;

- às solicitações personalizadas.

A intenção da flexibilidade do escopo do projeto, de acordo com os projetistas entrevistados, é atender às mais variadas situações construtivas e particularidades dos clientes visando sempre a racionalização da produção. Desta forma, o escopo do PPVV pode variar de um simples detalhamento genérico acompanhado de visitas à obra a um projeto extremamente detalhado.

A maioria dos projetos levantados na pesquisa apresenta o seguinte escopo básico:

- planta de conferência;

- planta de locação de eixos construtivos;

- plantas de marcação de 1a. e 2a. fiadas;

- plantas das passagens de elétrica e hidráulica;

- caderno de detalhes;

- caderno de elevações;

- caderno de recomendações e especificações técnicas.

Para exemplificar o método, será adotado o escopo básico acima relacionado, que será detalhado a seguir, mas cabe destacar que podem existir outros elementos, dependendo do projeto e do projetista. 


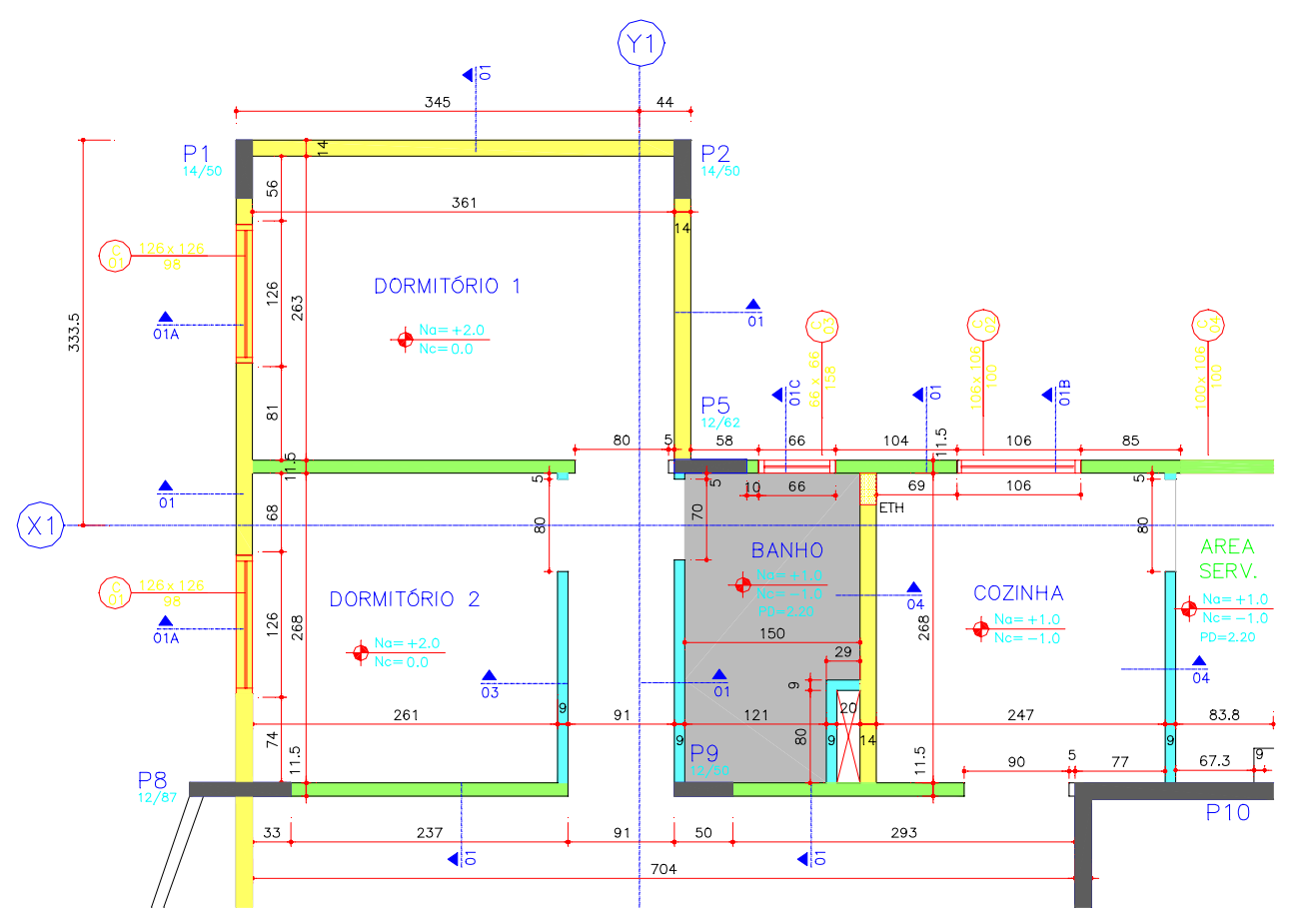

Figura 2. Representação gráfica da planta de conferência

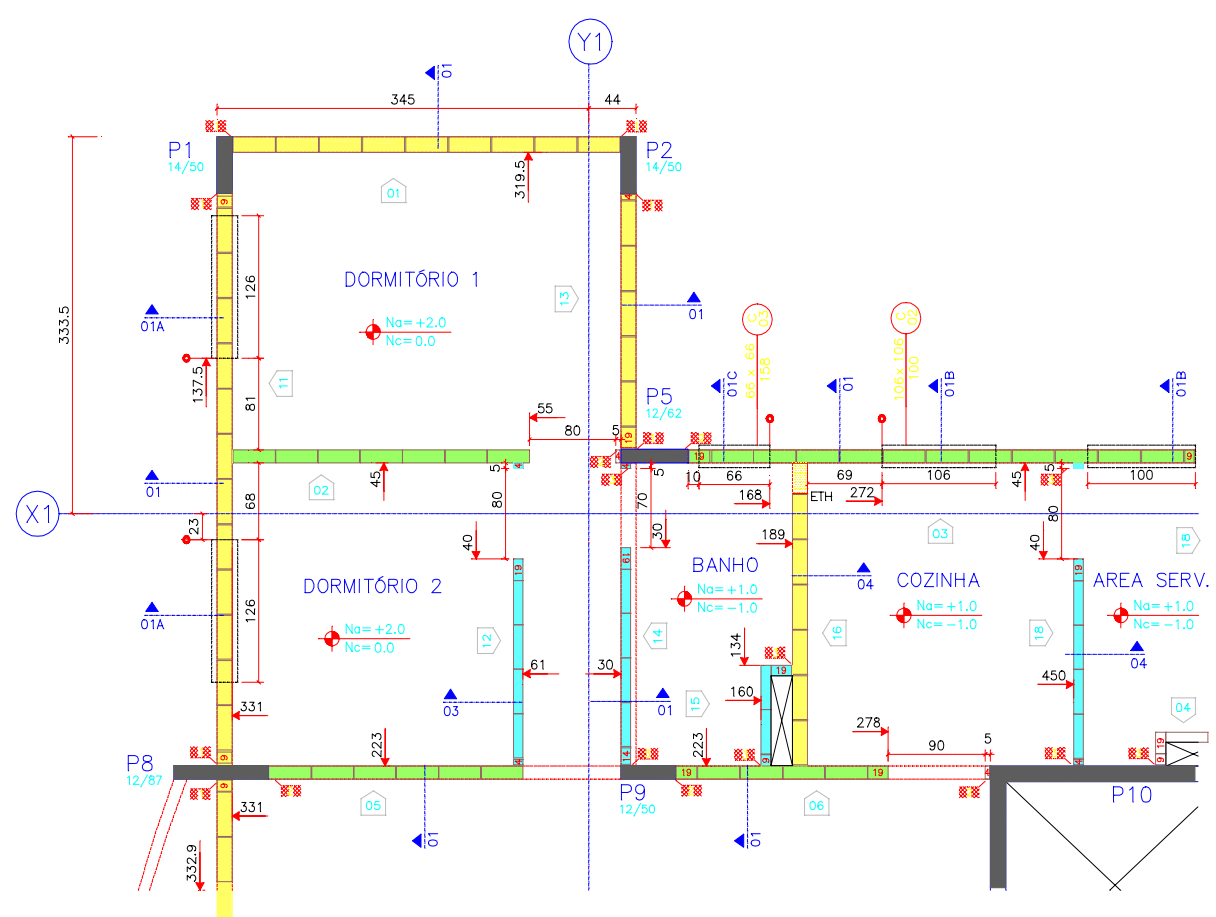

Figura 3 Representação gráfica da planta de marcação 


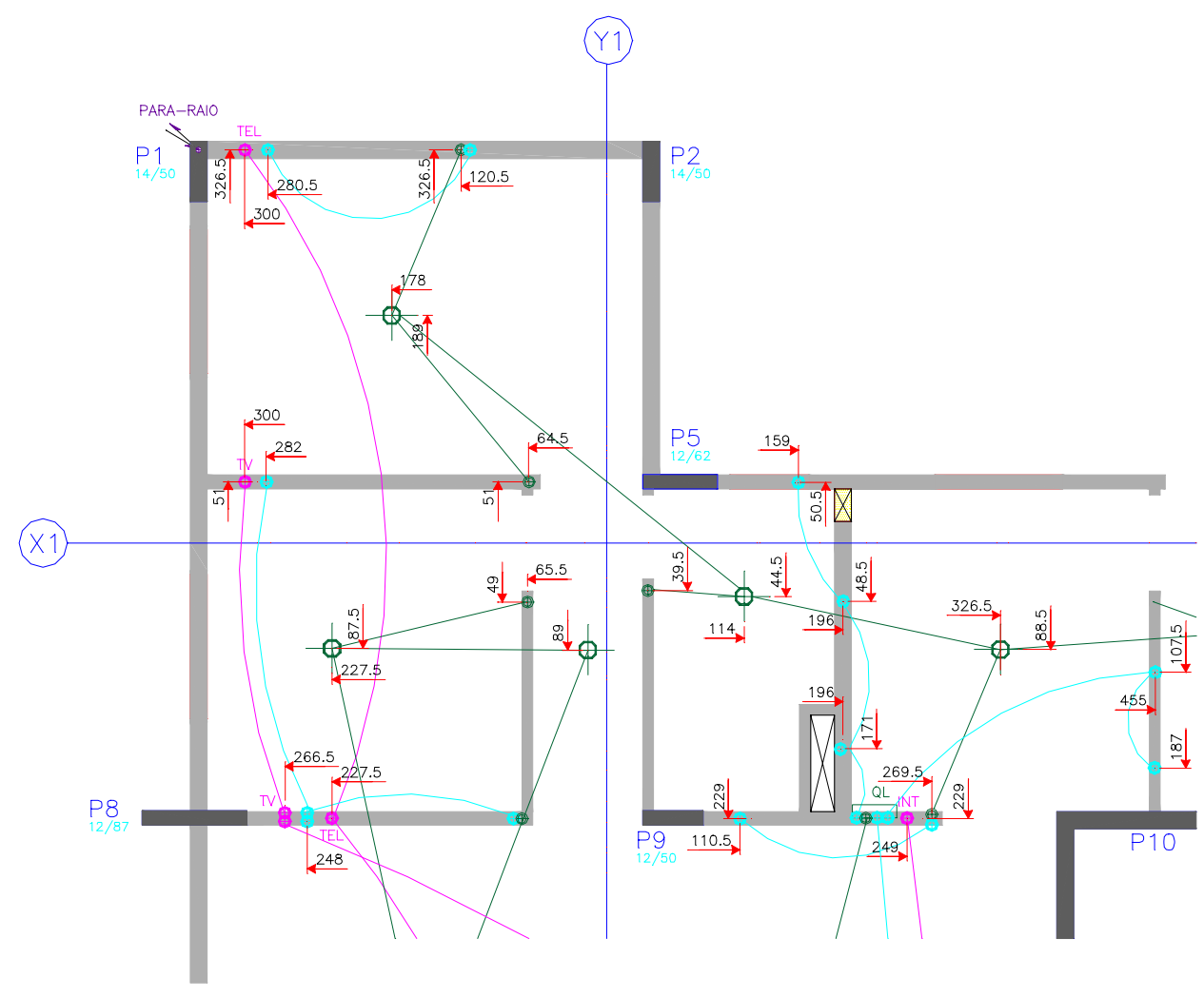

Figura 4. Representação gráfica da planta passagens elétricas
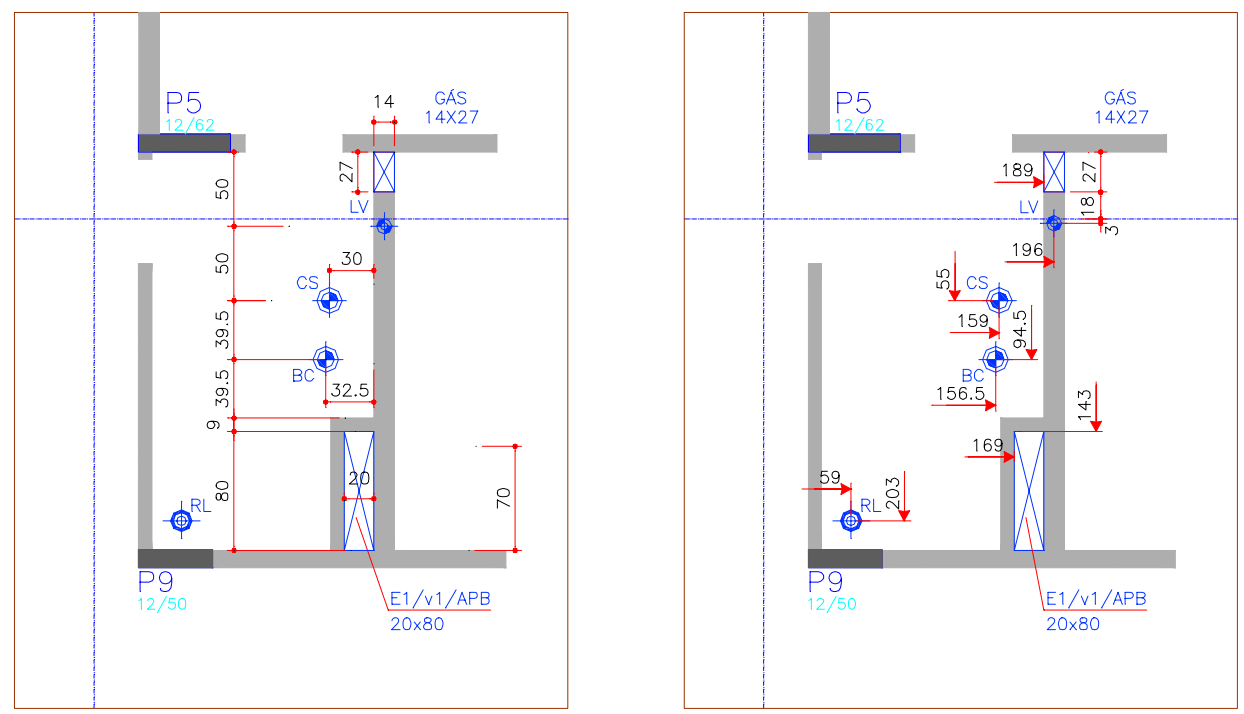

Figura 5. Representação gráfica das plantas de passagens 


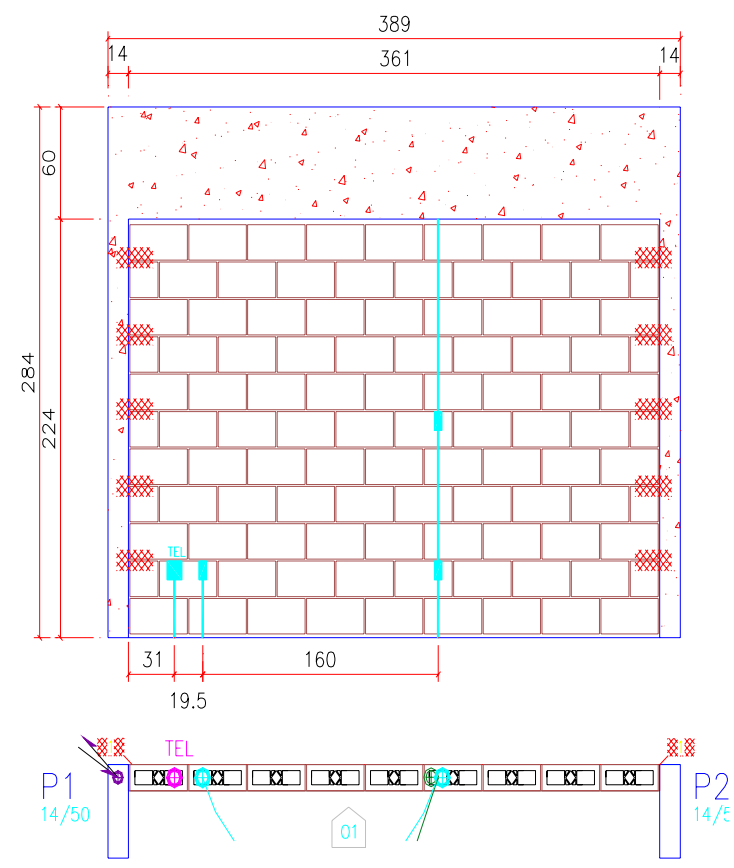

Figura 6. Representação gráfica das elevações

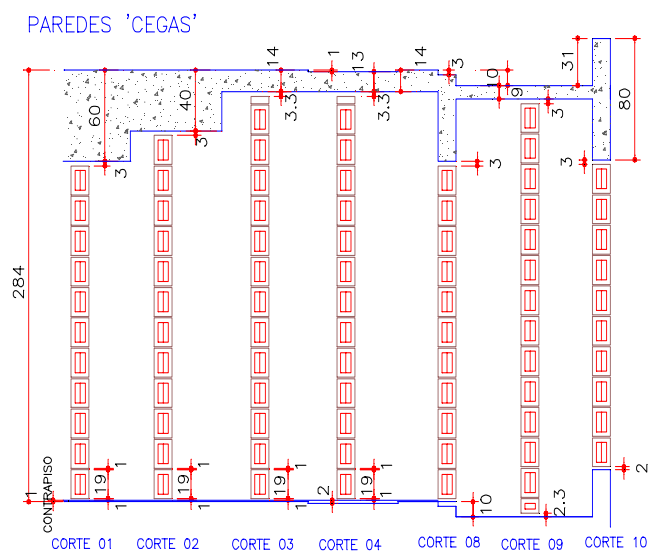

VAOS DE ALVENARIA / PEITORIL

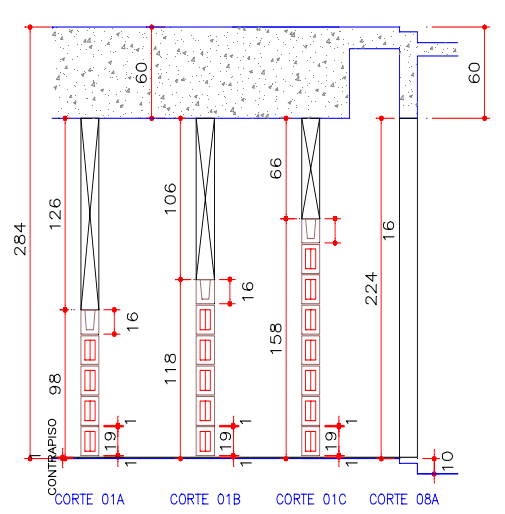

Figura 7. Representação gráfica de detalhe de modulação vertical 


\section{DOCUMENTOS: DE REGISTRO, CONTROLE E DESENVOLVIMENTO}

Para estruturar o método a ser elaborado foi desenvolvido um conjunto de documentos relacionados ao registro de informações, controle e desenvolvimento de projeto.

Estes documentos têm como base a prática de mercado evidenciada nos estudos de casos e a experiência profissional da autora e se encontram detalhados em Dueñas Peña (2003).

A relação dos documentos a serem desenvolvidos se encontra a seguir.

- Contato com o cliente:

- Registro de dados iniciais - RG1;

- Registro de dados técnicos - RG2.

Procedimentos para desenvolvimento de etapas:

- Estudo preliminar - PR-EP;

- Anteprojeto - PR-AP;

- Executivo - PR-EX;

- Detalhamento - PR-DET.

Diretrizes para elaboração dos itens componentes do PPVV :

- Elaboração da planta de conferência - EP1;

- Elaboração da planta de eixos - AP1;

- Elaboração da planta de marcação - AP2;

- Elaboração da planta de passagens elétricas - EX1;

- Elaboração da planta de passagens hidráulicas - EX2;

- Elaboração do detalhamento - DET1;

- Elaboração do caderno de elevações - DET2

- Elaboração do caderno de procedimentos e especificações técnicas - DET3.

Controle e gestão de informação:

- Relatório de compatibilização - RC - ETAPA

Controle de projetos:

- Controle de projeto - arquitetura - CP1

- Controle de projeto - estrutura - CP2

- Controle de projeto - hidráulica - CP3

- Controle de projeto - elétrica - CP4

Cabe destacar que os documentos apresentados servem apenas como referência para o desenvolvimento do método, podendo sofrer adaptações de acordo com as necessidades e características organizacionais de cada escritório.

\section{DEFINIÇÃO DO FLUXOGRAMA DE DESENVOLVIMENTO DO PPVV}

Todo projeto, seja ele de estrutura, arquitetura ou instalações, tem uma seqüência básica para a sua elaboração. Esta seqüência normalmente é dividida em etapas, sendo as mais usuais: estudo de viabilidade e concepção do produto; estudo preliminar; anteprojeto; executivo; detalhamento. 
De acordo com os dados obtidos nos estudos de casos, a introdução do PPVV, dentro do processo de desenvolvimento dos projetos, ocorre com maior freqüência nas etapas de anteprojeto e projeto executivo.

A introdução do PPVV nas etapas iniciais de desenvolvimento do processo de projeto amplia o seu potencial de racionalização, permitindo atitudes mais globais como, por exemplo, a adoção de uma modulação para todos os projetistas eliminando situações de ajustes dimensionais. Sendo assim, idealmente, o PPVV deve ser introduzido no processo de projeto juntamente aos demais projetistas.

Para a elaboração do método será considerada a introdução do PPVV no início do desenvolvimento dos projetos, ou seja, na etapa de estudo preliminar. A introdução do PPVV na etapa de estudo preliminar tem um caráter de consultoria técnica (análise conceitual da alvenaria) para os demais projetistas e para a empresa construtora. Posteriormente à consolidação dos estudos preliminares dos demais projetistas, o PPVV passa a ser desenvolvido enquanto projeto propriamente dito, a partir da análise crítica e compatibilização desses estudos preliminares.

Assim como os demais projetos, o PPVV apresenta uma seqüência de elaboração, a qual não foi claramente definida nos estudos de caso, devido aos métodos particularizados de cada escritório. Para o desenvolvimento do método será adotada a seguinte seqüência de etapas: estudo preliminar, anteprojeto, executivo, detalhamento e implementação e acompanhamento.

Para a elaboração do método foi necessário estruturar um fluxograma de desenvolvimento do PPVV, ilustrado na Figura 8, no qual são definidos os itens componentes de cada etapa e suas relações.

As etapas definidas serão caracterizadas a seguir de acordo com seu conteúdo, seqüência, procedimentos e materiais necessários para sua elaboração. 


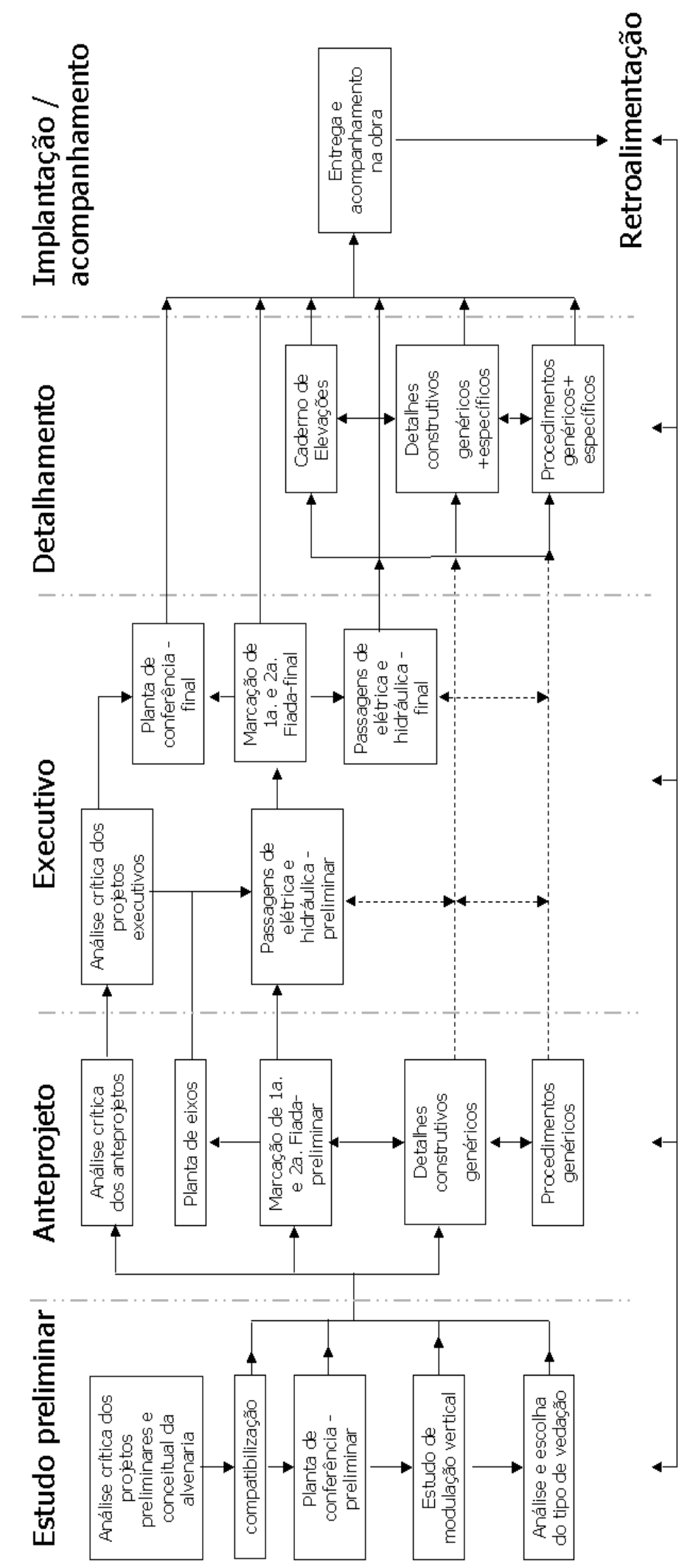

Figura 8. Fluxograma proposto para o desenvolvimento do PPVV 


\section{CARACTERIZAÇÃO DAS ETAPAS DE DESENVOLVIMENTO DO PPVV}

\section{ETAPA 1 - DADOS INICIAIS}

Ao estabelecer o primeiro contato com a empresa contratante, que, na maioria das vezes, se trata da empresa construtora, o projetista deve levantar os seguintes dados:

- a experiência da empresa com projetos para produção;

- o estágio de desenvolvimento dos projetos;

- $\quad$ solicitar uma planta de estrutura e de arquitetura do pavimento tipo ${ }^{2}$;

- bloco de alvenaria.

A partir da aprovação do contrato pelo cliente, torna-se necessário fazer um levantamento de informações relacionadas ao processo de projeto e à gestão de produção da empresa construtora, tais como:

- coordenador do projeto e suas atribuições;

- sistemas e tecnologias de informação ${ }^{3}$;

- padronização gráfica;

- estágio de desenvolvimento dos demais projetos.

Para desenvolver esta etapa consultar o documento RG1 que se encontra em Dueñas Peña (2003).

\section{ETAPA 2 - ESTUDO PRELIMINAR}

A etapa 1 serve basicamente para definir o que será feito e sob que condições; ou seja, nesta etapa são definidos o escopo do PPVV a ser desenvolvido, as ferramentas a serem utilizadas, os profissionais envolvidos e o cronograma dentro do qual os projetos serão desenvolvidos. A etapa 2 é caracterizada pela análise crítica e conceitual dos projetos e também pela sua compatibilização. Para tanto, o projetista deverá solicitar uma cópia impressa e eletrônica de todos os projetos desenvolvidos até então para análise.

Uma vez recebidos, os projetos devem ser analisados e compatibilizados. Esta análise dos projetos permite identificar os pontos críticos de cada projeto individualmente e principalmente se existe algum tipo de conflito decorrente da sobreposição dos projetos.

Além da identificação os pontos críticos dos projetos esta análise crítica e conceitual compreende a avaliação o futuro desempenho da alvenaria, sendo um dos pontos mais importantes do PPVV. Nesta análise o projetista irá verificar:

- projeto de estrutura: o comportamento da estrutura, principalmente no que diz respeito a possíveis deformações;

\footnotetext{
2 Na prática de mercado verifica-se que o PPVV é desenvolvido na maioria das vezes apenas para o pavimento tipo.

3 LUCAS JR (1993) define TI (tecnologia de informação) "referindo-se às máquinas, programas e aplicativos, procedimentos, pessoas e dados empregados na produção, disseminação e utilização da informação, tanto formal como informal, em uma organização. as tecnologias chave incluem computadores, dispositivos controlados por computadores, redes de telecomunicação, correio eletrônico e de voz , teleconferência e transmissão via fac-símile".

ALTER (1996) considera que o SI (sistema de informação) "é um sistema que utiliza a tecnologia de informação para capturar, transmitir, armazenar, recuperar, manipular ou mostrar informações utilizadas em um ou mais processos de negócio".
} 
- o relacionamento da estrutura com a alvenaria: tipos de ligações, juntas, etc;

- as tecnologias de produção, seqüências de elaboração e procedimentos executivos;

- a padronização modular de blocos, esquadrias, vergas e contra-vergas, vãos de arquitetura e estrutura;

- etc.

Após a análise e compatibilização dos projetos deve ser elaborada a planta de conferência e o estudo de modulação vertical.

Basicamente com a análise e compatibilização dos projetos e com a definição das espessuras dos blocos a serem utilizados nas vedações, o projetista de produção tem condições de elaborar a planta de conferência.

A planta de conferência elaborada, muitas vezes implica em pequenos ajustes nas plantas de estrutura e principalmente na de arquitetura. Tais ajustes deverão ser discutidos e aprovados pelo cliente e projetistas envolvidos. A aprovação destes ajustes deverá ser registrada formalmente para poder liberar o desenvolvimento da etapa seguinte do PPVV.

O estudo de modulação vertical envolve basicamente a análise conceitual da estrutura com a arquitetura. A partir deste estudo deverão ser avaliados os blocos de alvenaria mais apropriados para os vãos de estrutura e arquitetura definidos no projeto. No caso de a empresa construtora ainda não ter se decidido por um bloco específico, deverão ser analisados os blocos em estudo e através de uma análise técnica-comparativa escolher qual é o mais apropriado. Assim como na planta de conferência, o estudo de modulação vertical muitas vezes implica em pequenos ajustes de medidas nos projetos de arquitetura e estrutura, alterações de espessuras de lajes e alturas de vigas, de dimensões e posicionamento de esquadrias são muito freqüientes e deverão ser discutidas e aprovadas pelos projetistas e cliente.

Após a elaboração destes itens e da compatibilização dos projetos, deve ser elaborado um relatório de compatibilização, enumerando e explicando todos os pontos críticos identificados, que deverá ser encaminhado a todos os projetistas e coordenador. Devido à importância das informações do relatório, é aconselhável a realização de uma reunião com todos os projetistas para discutir o relatório e definir em conjunto as soluções mais apropriadas para cada caso. Com base nas decisões tomadas cabe a todos os projetistas revisarem os seus projetos, quando necessário, e posteriormente darem início ao desenvolvimento da etapa seguinte, de anteprojeto.

Nesta reunião, além da apresentação do material elaborado e do relatório de compatibilização, deverá ser apresentado e discutido o escopo mínimo de cada projeto (estrutura, instalações, arquitetura, etc) para cada etapa do processo de projeto (anteprojeto, executivo, detalhamento, etc) para garantir os dados de entrada necessários para o desenvolvimento do PPVV de acordo com o cronograma do empreendimento. 


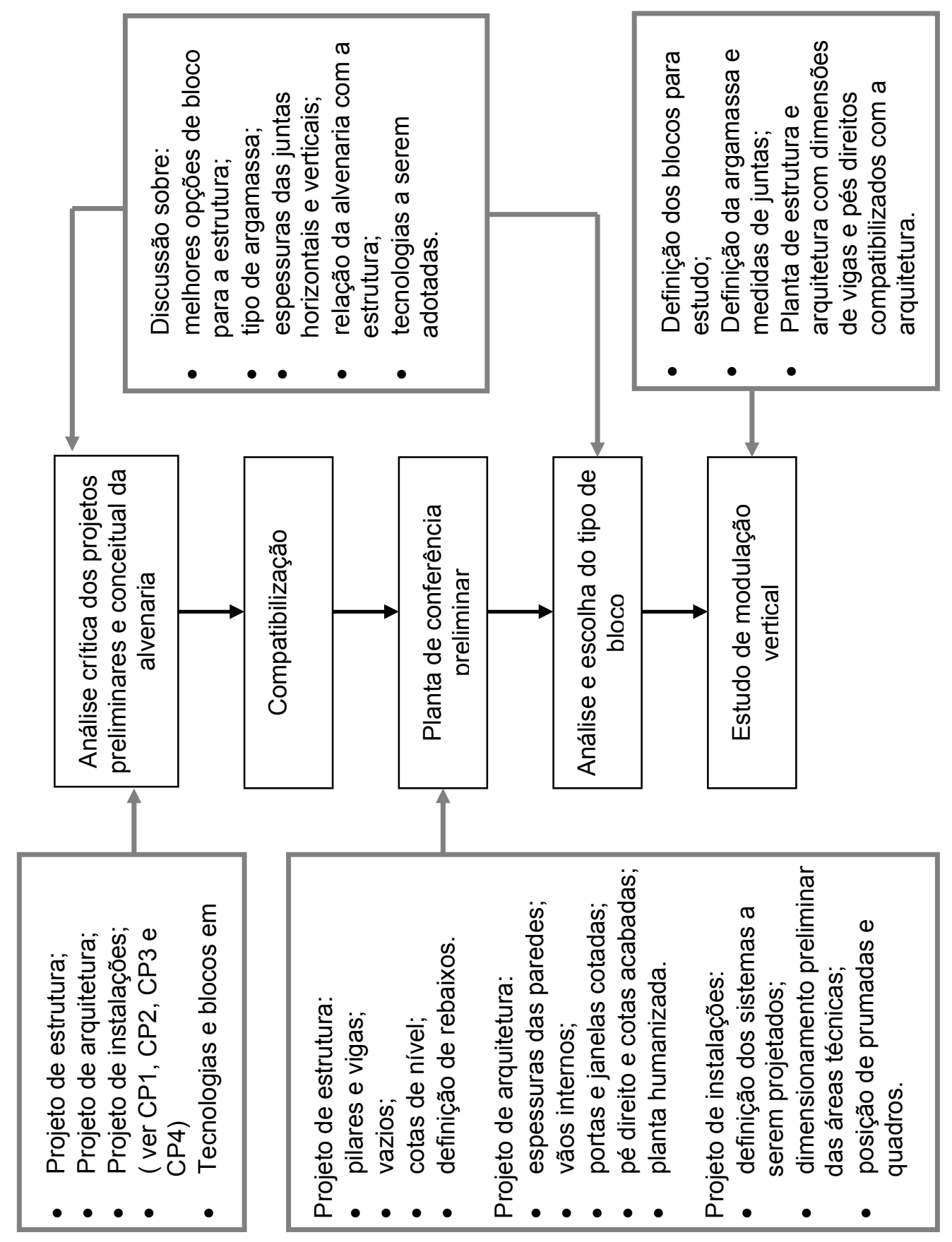

Figura 9. Dados de entrada necessários para a elaboração da etapa de estudo preliminar do PPVV. 
Para auxiliar, formalizar e registrar a definição do escopo mínimo de cada projetista foram elaborados documentos de controle de projeto (CP1 a CP4). Estes documentos definem quais informações devem constar nos projetos por etapa de desenvolvimento, garantindo que as informações necessárias específicas para o desenvolvimento do PPVV sejam contempladas. Os dados contidos nos documentos de controle de projeto devem ser discutidos com os demais projetistas e alterados quando necessário.

Estes documentos foram desenvolvidos para auxiliar o desenvolvimento do PPVV especificamente, sendo assim, o seu conteúdo é direcionado e não abrange o conteúdo total dos projetos 4 .

Caso estes documentos fossem desenvolvidos com um conteúdo mais abrangente, eles serviriam como ferramenta de coordenação, controle e planejamento do processo de projeto, tornando desnecessário este controle por parte do projetista de produção.

Para elaboração desta etapa, utilizar o PR-EP e os documentos a ele relacionados que se encontram em Dueñas Peña (2003).

\section{ETAPA 3 - ANTEPROJETO}

A etapa 3 é caracterizada pela análise e compatibilização dos projetos já discutidos anteriormente. Para dar início a esta etapa é necessário:

- aprovação da etapa anterior pelo cliente;

- anteprojetos de arquitetura, estrutura e instalações contemplando solicitações da reunião de compatibilização da etapa anterior;

- definição do bloco de alvenaria a ser utilizado.

Uma vez recebidos os anteprojetos dos demais projetistas eles devem ser novamente analisados e compatibilizados. Nesta nova análise deve-se verificar se todos os pontos críticos discutidos anteriormente foram solucionados e revisados.

Assim como na etapa anterior deve-se elaborar um relatório de compatibilização contendo os eventuais problemas levantados nesta nova fase. Este relatório deve ser encaminhado aos projetistas para posteriormente ser discutido em reunião. Sempre que possível, para evitar reuniões demasiadamente longas, os assuntos menos críticos devem ser discutidos e resolvidos diretamente com o projetista responsável. Conforme tais assuntos forem sendo resolvidos, as soluções adotadas devem ser registradas e enviadas ao projetista e cliente para formalizar a solução adotada.

Depois de realizada a compatibilização dos anteprojetos dos demais projetistas deve-se revisar a planta de conferência, caso necessário. Assim que a planta de conferência estiver compatível com as novas informações e que o bloco a ser utilizado tenha sido definido, são elaboradas as plantas de marcação de $1^{\mathrm{a}}$ e $2^{\mathrm{a}}$ fiadas. Estas plantas deverão ser apresentadas ao cliente para aprovação, dentro de um caráter preliminar, pois ainda serão revisadas após a elaboração das plantas de passagens elétricas e hidráulicas.

\footnotetext{
${ }^{4}$ O PPVV normalmente é desenvolvido apenas para o pavimento tipo; a análise dos projetos não abrange todos os pavimentos e, desta forma, boa parte da compatibilização e análise crítica dos projetos fica sob a responsabilidade do coordenador dos projetos.
} 
Para a elaboração das plantas de marcação de 1a. e 2a. fiadas devem estar definidos:

- blocos e espessuras das paredes;

- definição dos eixos de locação da alvenaria;

- especificações das juntas: verticais e horizontais;

- tipo de amarração: entre paredes e estrutura;

- dimensões e posicionamento de prumadas, quadros e shafts;

- dimensões e posicionamento das esquadrias e portas;

- folgas para a instalação de esquadrias e portas;

- aprovação da planta de conferência.

As plantas de marcação devem ser elaboradas com base nos dados contidos no AP2 que será apresentado posteriormente.

Nas plantas de marcação, assim como, na plantas de conferência, eixos e passagens deve ser inserido um quadro de controle dos projetos utilizados para a elaboração da planta em questão. Este quadro permite, principalmente para o engenheiro da obra, verificar quais folhas e que projetos foram utilizados e, principalmente verificar se foram atendidas e compatibilizadas as últimas versões (revisões) dos projetos. Desta forma, se por algum motivo qualquer o projetista de produção não tiver recebido e contemplado a revisão de algum projeto específico, esta incompatibilidade será facilmente identificada pela equipe de produção. Ver Figura 10 .

\begin{tabular}{|l|l|l|l|}
\hline \multicolumn{1}{|c|}{ PROJETO } & FOLHA & DATA & REVISÃO / DATA \\
\hline ARQUITETURA & & & \\
\hline ESTRUTURA & & & \\
\hline ELÉTRICA & & & \\
\hline HIDRÁULICA & & & \\
\hline
\end{tabular}

Figura 10. Quadro de controle de projetos.

Nesta etapa é dado início ao desenvolvimento dos detalhes e dos procedimentos e especificações técnicas do projeto. Para tanto, deve-se verificar se a construtora possui procedimentos e detalhes padronizados que devem ser utilizados para a elaboração do PPVV. Os procedimentos e detalhes genéricos do PPVV devem ser discutidos com a equipe de produção ao longo de sua elaboração.

Para finalizar esta etapa deve ser agendada uma reunião de compatibilização para a apresentação e discussão do relatório e do material elaborado.

Para elaboração desta etapa, utilizar o PR-AP e os documentos a ele relacionados que se encontram em Dueñas Peña (2003). 


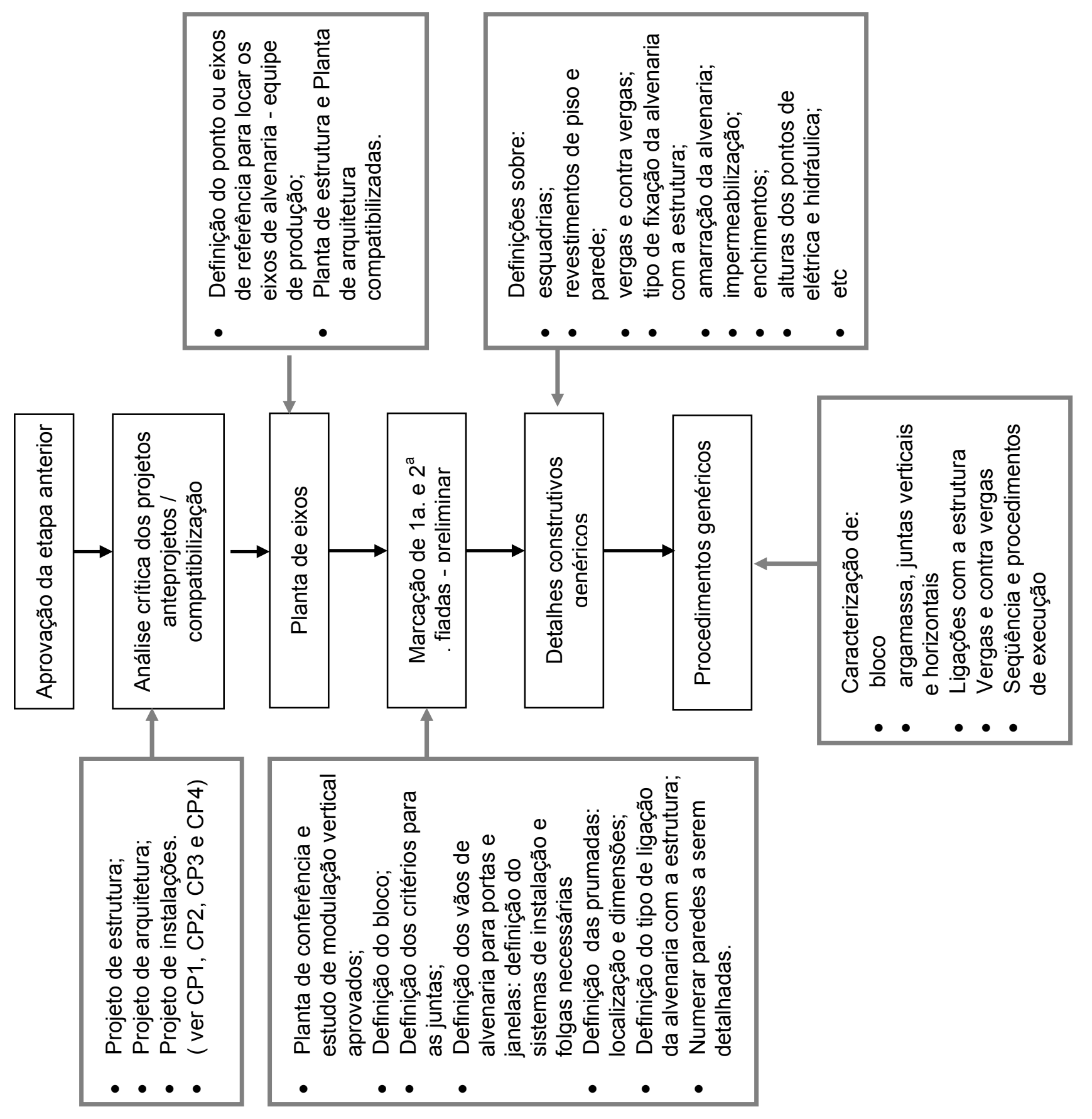

Figura 11. Dados de entrada necessários a elaboração da etapa de anteprojeto do PPVV. 


\section{ETAPA 4 - PROJETO EXECUTIVO}

Esta fase é caracterizada pela compatibilização final dos projetos e pela entrega parcial do PPVV.

Para dar início a esta etapa é necessário:

- aprovação da etapa anterior pelo cliente;

- projetos executivos de arquitetura, estrutura e instalações contemplando solicitações da reunião de compatibilização anterior;

Novamente os projetos são analisados e compatibilizados e suas incompatibilidades são registradas no relatório de compatibilização. Estas incompatibilidades devem ser comunicadas ao cliente e projetista e resolvidas o mais rápido possível, para dar continuidade ao desenvolvimento do PPVV.

Para dar continuidade ao desenvolvimento do PPVV é elaborada a planta preliminar de passagens de elétrica e hidráulica. A elaboração destas plantas muitas vezes implica em pequenos ajustes nas plantas de marcação e conferência que deverão ser revisadas. Após a revisão e finalização das plantas de marcação, são finalizadas as plantas de passagens elétricas e hidráulicas.

Ao longo desta etapa é dada continuidade ao desenvolvimento dos detalhes e procedimentos, que deverão ser sempre discutidos com a equipe de produção ou responsável.

Após a elaboração destes itens, deve ser agendada uma reunião para a entrega dos seguintes itens do PPVV:

- relatório final de compatibilização;

- planta de conferência - final;

- planta de locação dos eixos;

- plantas de marcação de $1^{\mathrm{a}}$ e $2^{\mathrm{a}}$ fiadas - final;

- plantas de passagens de elétrica e hidráulica - final.

Este material deverá ser analisado pelo cliente e pela equipe de produção. No caso de solicitações de revisões, estas deverão ser avaliadas pelo projetista e atendidas sempre que necessário.

Para elaboração desta etapa, utilizar o PR-EX e os documentos a ele relacionados que se encontram em Dueñas Peña (2003). 


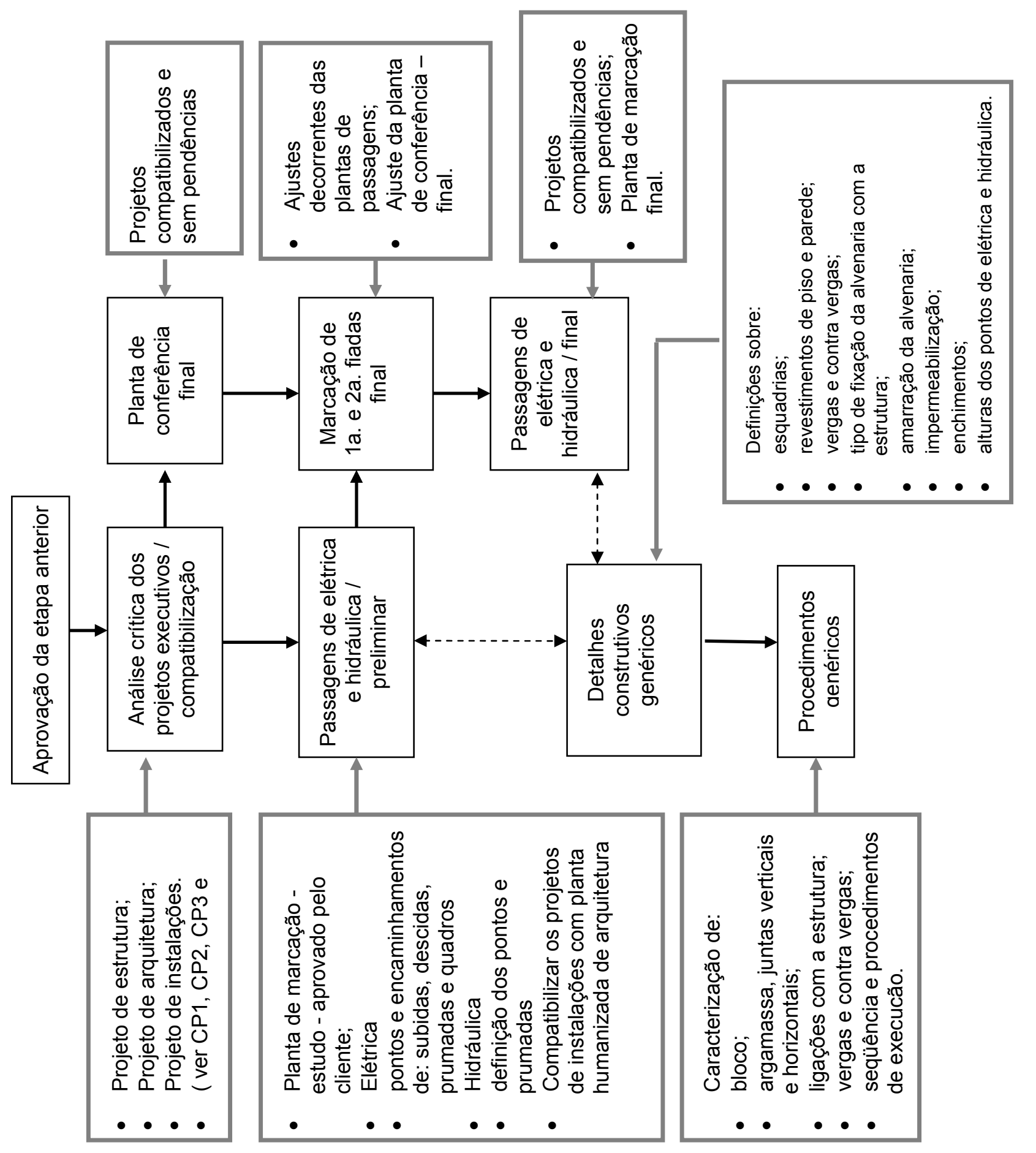

Figura 12. Informações necessárias para a etapa de executivo. 


\section{ETAPA 5 - DETALHAMENTO}

O material entregue na etapa anterior deve ser analisado e aprovado pelo cliente, com a sua aprovação passa a ser elaborado o caderno de elevações e finalizados o caderno de detalhes e de procedimentos e especificações técnicas que foram discutidos ao longo das etapas com a equipe de produção.

Para elaboração desta etapa, utilizar o PR-DET e os documentos a ele relacionados que se encontram em Dueñas Peña (2003).

\section{ETAPA 6 - IMPLANTAÇÃO, ACOMPANHAMENTO E RETROALIMENTAÇÃO}

A entrega final e completa do PPVV deve ser agendada com a equipe de produção. No caso de a empresa construtora possuir procedimentos formalizados de entrega que obriguem a efetuar a entrega para algum departamento específico ou para o responsável pela atividade de projeto na empresa, o projetista deve solicitar uma reunião com a equipe de produção para apresentar o projeto e esclarecer eventuais dúvidas.

Esta entrega tem um caráter explicativo, principalmente nos casos onde a equipe de produção não teve uma participação significativa durante o processo de projeto e precisa ser conscientizada do conteúdo, processo construtivo e potencialidades do PPVV.

Para garantir o entendimento e utilização do projeto, ao final da apresentação devem ser agendadas com o engenheiro responsável visitas de acompanhamento durante a utilização do projeto. Tais visitas além de auxiliares no entendimento do projeto, possibilitam ao projetista a retroalimentação do projeto através da analise crítica do impacto do PPVV na produção e na equipe de produção.

Esta análise permite ao projetista identificar os pontos que podem ser melhorados no projeto PPVV referentes a conteúdo e forma de apresentação.

O conteúdo do PPVV pode variar de acordo com as necessidades específicas de cada obra; tais necessidades deverão ser identificadas durante o processo de elaboração do PPVV. Quando a participação da equipe de produção durante a elaboração do projeto não for significativa, cabe ao projetista avaliar e identificar durante a utilização a ausência de informações relevantes ou a existência de informações que não estão sendo utilizadas. Em ambos os casos e sempre que possível o PPVV deve ser adequado, principalmente no caso de ausência de informações.

No caso das informações que não estão sendo utilizadas, devem ser identificados os motivos pelos quais a informação não está sendo utilizada e ajustar o projeto quando necessário.

As informações obtidas nas visitas à obra são cadastradas para serem utilizadas como parâmetros balizadores para outros projetos da mesma construtora ou de construtoras com perfis semelhantes. 


\section{CONCLUSÕES}

O método proposto tem como intenção balizar o desenvolvimento do PPVV, como referência para projetistas e também servir como ferramenta de controle de contratação e análise crítica para as empresas construtoras.

A estrutura do método proposto foi baseada no processo de desenvolvimento de projetos identificado no mercado e em sistemas de controle da qualidade utilizados por escritórios de projeto certificados ou em processo de certificação.

O desenvolvimento do PPVV foi dividido em etapas, de acordo com a seqüência executiva do seu escopo básico e em função das informações necessárias para a sua elaboração provenientes dos demais projetos. Através da caracterização da divisão de etapas proposta, buscou-se exemplificar a sua inserção do PPVV no processo de projeto e apresentar as principais dificuldades encontradas durante o seu desenvolvimento.

Quanto ao escopo básico mencionado, sua definição foi baseada nos dados obtidos nos estudos de caso e representa um conteúdo básico integrante da grande maioria dos projetos elaborados pelos escritórios entrevistados. Cabe ressaltar que atualmente o mercado da cidade de São Paulo conta com a atuação de apenas seis ou sete escritórios de destaque (três dos quais foram estudos de caso) e, sendo assim, pode-se considerar que o escopo básico definido representa a prática consolidada no mercado.

Ainda quanto ao conteúdo, como identificado nos estudos de casos, o escopo básico do PPVV atualmente desenvolvido no mercado não incorpora todos os elementos ligados à organização do canteiro e ao planejamento e controle da obra. Este fato transforma o projeto para produção em um projeto de produto com caráter compatibilizador, contrariando os conceitos de projetos para produção.

Estes itens, especificamente, costumam ser desenvolvidos pelo gerente da obra. No entanto, o projetista pode, caso seja solicitado pela construtora, dar suporte ao seu desenvolvimento com sugestões e discussões técnicas e incorporando as decisões tomadas ao PPVV, que desta forma passaria a ser caracterizado plenamente como projeto para produção.

Esta complementação do PPVV depende das necessidades da empresa contratante e da participação da equipe de produção durante o desenvolvimento dos projetos e também da sua retroalimentação ao projetista de alvenaria especificamente, pois sem as informações advindas da obra não é possível desenvolver documentos relativos à organização, planejamento e controle da obra que sejam pertinentes e aplicáveis. A inclusão destes itens no escopo do PPVV deve ser avaliada do ponto de vista da produção e requer uma pesquisa de campo minuciosa envolvendo a análise crítica da utilização do PPVV em relação ao seu conteúdo e à estrutura de gestão da produção das empresas construtoras.

Observa-se, infelizmente, que a participação da equipe de produção no processo de projeto ainda é pouco abrangente. Este fato é crítico, não apenas para o projetista de produção, mas para todos os projetistas que não têm retorno da análise crítica e eventuais deficiências observadas pela equipe de produção durante a utilização de seus projetos. 
Os projetistas devem buscar o estreitamento da comunicação com a equipe de produção, para avaliar as reais necessidades da obra e estabelecer a abrangência do PPVV, e também para obter a retroalimentação do projeto baseada na análise crítica fornecida pela equipe de produção.

Os PPVV elaborados até o momento não contam ainda com a avaliação de desempenho das soluções técnicas adotadas, sendo esta mais uma sugestão de melhoria para o desenvolvimento do PPVV e também como tema de trabalho de pesquisa, analisando e comparando o desempenho da alvenaria e de detalhes construtivos específicos que foram adotados nos últimos anos em função do PPVV.

O projeto para produção, dentro do processo de projeto, apresenta um papel nitidamente compatibilizador e, por apresentar esta característica, acaba intervindo diretamente, enquanto análise crítica, nos demais projetos. Deve-se esclarecer que o PPVV é contratado com a intenção de garantir a racionalização da produção e a compatibilização dos projetos, sendo que não compete ao PPVV suprir informações de projetos deficientes, e sim, apontar as eventuais deficiências e pontos críticos dos projetos ou da coordenação, contribuindo assim para a melhoria da qualidade técnica dos projetos, do processo de projeto e, conseqüentemente, da produção.

Outra atuação polêmica do PPVV está relacionada à coordenação de projetos. A relação intrínseca do projetista de produção com a equipe de produção e equipe de projeto, associada ao seu conhecimento técnico facilitam a atuação do projetista de produção na coordenação de projetos. Esta atuação, mesmo que de forma sutil, ocorre na prática, no entanto, é evitada pelos projetistas quando não faz parte do seu escopo de contratação. A coordenação dos projetos é oferecida pela maioria dos escritórios de projetos para produção de vedações; no entanto, este serviço nem sempre é contratado, por estar vinculado ao escopo de serviços do projetista de arquitetura.

A contratação do projetista de vedações, de acordo com os estudos de caso, ocorre nas etapas de executivo e anteprojeto. No entanto, em função da ampliação do seu potencial de racionalização, foi proposto no método que a contratação deve ocorrer nas fases iniciais do desenvolvimento dos projetos. Acredita-se que, futuramente, assim como as empresas mudaram a contratação da fase de executivo para a de anteprojeto, esta prática seja consolidada em função da constatação prática por parte das empresas construtoras das melhorias obtidas no processo de projeto e de produção.

O método proposto compreende o PPVV com o conteúdo básico que normalmente vem sendo desenvolvido e utilizado no mercado. Acredita-se que este método possa ser aplicado por empresas de projeto, com pequenos ajustes de formatação. Cabe ressaltar que o PPVV desenvolvido no mercado ainda não atende plenamente às informações relacionadas ao planejamento e controle da obra, sendo este um item a ser discutido e aprimorado pelos escritórios de projeto, com base em trabalhos de pesquisa e também através de um contato mais próximo com as equipes de produção.

Apesar de ter sido desenvolvido para as vedações verticais em alvenaria, com alguns ajustes, este método pode ser adaptado para outros tipos de vedações verticais, tais como as vedações verticais em gesso acartonado. 
Este trabalho de pesquisa tem um caráter prático e esclarecedor em relação ao desenvolvimento do PPVV e sua inserção no processo de projeto e vem complementar os demais trabalhos de pesquisa já desenvolvidos relacionados a este tema.

Neste sentido, o método proposto torna-se uma ferramenta auxiliar na melhoria da qualidade da produção das vedações verticais e também abre novas perspectivas para discussões e pesquisas no meio acadêmico.

\section{REFERÊNCIAS BIBLIOGRÁFICAS}

CONSTRUCTION INDUSTRY INSTITUTE. Constructability: a primer. 2.ed. austin, 1987. (CII publication, n.3-1)

DUEÑAS PEÑA, M. Método para a elaboração de projetos para produção de vedações verticais em alvenaria.160p. Dissertação (Mestrado) - Escola Politécnica, Universidade de São Paulo. São Paulo, 2003.

EPUSP-ENCOL. Recomendações para o projeto construtivo de paredes de vedação em alvenaria: procedimentos para elaboração e padrão de apresentação. Relatório CPqDCC, no. 20.053- EP/EN-7, São Paulo, EPUSP-PCC, 1991.

EPUSP-SCHAHIN CURY. Diretrizes para a elaboração do projeto de alvenaria de vedação. Relatório CPqDCC, no. 20.085 - EP/SC-1, São Paulo, EPUSP-PCC, 1995

FRANCO, L.S. O projeto de vedações verticais: características e a importância para a racionalização do processo de produção. In: I SEMINÁRIO TECNOLOGIA E GESTÃO NA PRODUÇÃO DE EDIFÍCIOS: Vedações Verticais - São Paulo, 1998. Anais. EPEUSP/PCC, 1998. P221-236

Notas de aula da disciplina de Tecnologia de produção de vedações verticais - TG004. São Paulo: EPUSP, 2002. Disponível em < http://tgpmba.pcc.usp.br/TG-004/Aulas\%204\%20e\%205\%20-\%20Folhetos.pdf> Acesso, abril de 2003

MELHADO, S.B.\&VIOLANI,M.A. A qualidade na construção civil e o projeto de edifícios. São Paulo, EPUSP, 1992. (TT/PCC/02).

SABBATINI, F.H. Desenvolvimento de métodos, processos e sistemas construtivos.1989. Tese (Doutorado) - Escola Politécnica, Universidade de São Paulo. São Paulo, 1989.

. A industrialização e o processo de produção de vedações: utopia ou elemento de competitividade empresarial? In: I SEMINÁRIO TECNOLOGIA E GESTÃO NA PRODUÇÃO DE EDIFÍCIOS: Vedações Verticais - São Paulo, 1998. Anais. EPEUSP/PCC, 1998.

\section{BIBLIOGRÁFIA CONSULTADA}

EPUSP-ENCOL. Desenvolvimento de um novo processo construtivo em alvenaria estrutural não armada de blocos de concreto: execução da alvenaria. Relatório CPqDCC, no. 20.074-EP-EN5, São Paulo, EPUSP-PCC, 1992.

EPUSP-ENCOL. Recomendações para o projeto construtivo de paredes de vedação em alvenaria: procedimentos para elaboração e padrão de apresentação. Relatório CPqDCC, no. 20.053- EP/EN-7, São Paulo, EPUSP-PCC, 1991. 
EPUSP-ENCOL. Recomendações para construção de paredes de vedação em alvenaria. Relatório CPqDCC, no. 20.013 - EP/EN-1, São Paulo, EPUSP-PCC, 1988.

EPUSP-ENCOL. Ferramentas e procedimentos para a execução da alvenaria. Relatório CPqDCC, no. 20.056 - EP/EN-5, São Paulo, EPUSP-PCC, 1991.

EPUSP-ENCOL. A execução da alvenaria. Relatório CPqDCC, no. 20.074 - EP/EN5, São Paulo, EPUSP-PCC, 1992.

EPUSP-SCHAHIN CURY. Diretrizes para a elaboração do projeto de alvenaria de vedação. Relatório CPqDCC, no. 20.085 - EP/SC-1, São Paulo, EPUSP-PCC, 1995

EPUSP-SICAL. Desenvolvimento de um método construtivo de alvenaria de vedação de blocos de concreto celular autoclavados". Relatório CPqDCC, no.20.081, EP/SICAL-1, São Paulo, EPUSP-PCC, 1994.

EPUSP-TEBAS. Desenvolvimento do elemento parede / desenvolvimento da tecnologia construtiva. Relatório CPqDCC, no. 20.002 - EP/TC1, São Paulo, EPUSP-PCC, 1987

. Alvenarias de vedação. In: Qualidade\& Produtividade na construção civil. São Paulo, EPUSP/ITQC, 1994.

. Alvenarias de vedação. In: CONGRESSO BRASILEIRO DE ENGENHARIA DE AVALIAÇÕES E PERÍCIAS - São Paulo, 1997.

. O projeto de vedações verticais: características e a importância para a racionalização do processo de produção. In: I SEMINÁRIO TECNOLOGIA E GESTÃO NA PRODUÇÃOO DE EDIFÍCIOS: Vedações Verticais - São Paulo, 1998. Anais. EPEUSP/PCC, 1998. P221-236 